\title{
Exploring on the measurement methods of shale gas content
}

\author{
Xue Lina ${ }^{1, a}$, Chen Bin ${ }^{2, b}$ \\ ${ }^{1}$ Southwest Petroleum University, Sichuan 610500, China \\ ${ }^{2}$ Liaohe Oilfied of CNPC, Liaoning 110300, China \\ a1564767547@qq.com_b309564326@qq.com
}

Keywords: shale gas; gas content measurement method; desorption method; metering device; automatic measurement

\begin{abstract}
Shale gas content is a key parameter to calculate shale gas in situ, it has an important significance to the evaluation of shale gas content and the prediction of resource reserves. Currently, the methods of determination shale gas content mainly include desorption method, isothermal adsorption method and the logging interpretation method. The manual measuring equipment used in shale gas content measurement is based on the principle of drainage method. This paper mainly introduce the methods of measuring the shale gas content, and focus on the discussion of the basic principle of the determination of gas content in shale by desorption method. At the same time, analyzed and compared with the existing domestic shale gas content measurement device, in the era of industrial automation, the automatic measurement of shale gas content is not only a trend of the development of shale gas content measurement method, but also improve the efficiency and precision of the shale gas content measurement, it helps to improve the accuracy of shale gas resource assessment, and obtain an unattended shale gas metering system.
\end{abstract}

\section{Shale gas content and measurement methods.}

Shale gas content refers to the volume of natural gas in the shale of the unit mass at $0{ }^{\circ} \mathrm{C}$, $101.325 \mathrm{kPa}$. According to the state of occurrence, shale gas includes adsorbed gas, free gas and dissolved gas. According to the measurement process, divided into the desorbed gas, residual gas and lost gas $^{[1]}$.

At present, the determination of shale gas content in the world is mainly about the measurement of the desorbed gas, the residual gas and the lost gas. desorbed gas refers to the gas volume from a certain quality of gas shale samples which were loaded and sealed into the desorption tank, under a certain temperature, pressure and time; residual gas refers to the volume of gas released by a certain mass of shale samples after desorption; Lost gas refers to the volume of gas that desorbed during the time between a certain quality of the shale samples beginning to desorption from the bottom of the well and sealing the tank, we can use the USBM method to calculate the regression ${ }^{[1]}$. Determination of gas content in shale is divided into direct method (desorption method) and indirect method (isothermal adsorption experiment method and well logging interpretation). 


\section{Desorption measurement of shale gas}

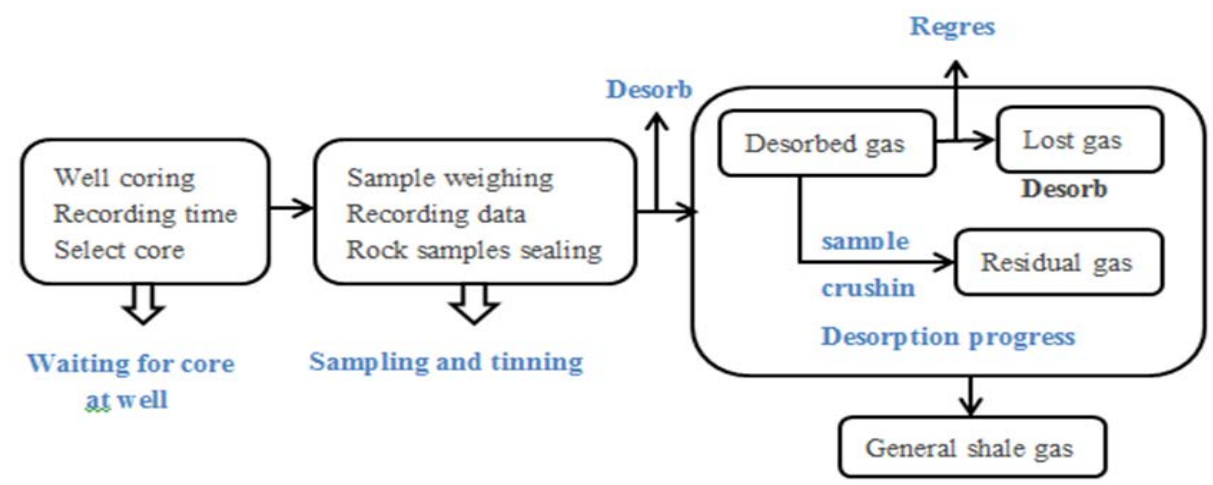

Fig.1 Shale Gas desorption measurement flow diagram

Desorption methods included USBM method, Modified direct method, Smith-Williams method and Curve-fitting method .etc. Their fundamentals are the USBM method. The shale gas content in desorption methods was made of desorption gas, residual gas and lost gas. As shown in Figure 1 is Shale Gas desorption measurement flow diagram.

Desorption measurements was completed primarily on the spot of drill core, accurately record the time of tripping out, tripping, core arriving at the Iguchi and the end of tinning in the drilling process. In order to ensure the accuracy of field analytical testing, drilling for core processes should be as short as possible, core out of the hole should be quickly placed in sealed tanks, and fine quartz sand filling solution suction tank after the gap seal, and put the good sealing desorption canister into the thermostat of Shale Gas testing system which has reached the set temperature, in which has shale samples, connecting the desorption canister and the gas metering detection device with the hose. And begin to desorb, and collect the relevant data for timing until the end of desorption.

Only after the natural desorption ended can we measure the residual gas content. Take part of samples and put it in the sealed sample tank which is used for residual gas content test. Then smash it until we get the certain amount. After all the steps above, leave it static 5 minutes at least. Then connect to the gas metering device and record the relevant data. Keep this step until the desorption ended 。 The average data is the residual gas content.

Put the general desorption gas and general residual gas, which was got from field desorption into the formula (1), and converted to standard state (Temperature $0^{\circ} \mathrm{C}$, Pressure $101.325 \mathrm{kPa}$ ):

$$
\mathrm{V}_{\mathrm{s}}=\frac{273.15 \mathrm{P}_{\mathrm{m}} \cdot \mathrm{V}_{\mathrm{m}}}{101.325 \cdot\left(273.15+\mathrm{T}_{\mathrm{m}}\right)}
$$

(in the formula: $V_{s}$ is the volume of gas at the standard state, $\mathrm{cm}^{3} ; \mathrm{P}_{\mathrm{m}}$ is the atmospheric pressure, $\mathrm{kPa} ; \mathrm{T}_{\mathrm{m}}$ is the environment temperature, ${ }^{\circ} \mathrm{C} ; \mathrm{V}_{\mathrm{m}}$ is the volume of gas, $\mathrm{cm}^{3}$ ).

Thus the formula of desorption gas content and residual gas content is:

$$
V_{d}=\frac{V_{\mathrm{sd}}}{m_{d}}
$$

(in the formula: $V_{d}$ is the desorption gas content, $\mathrm{cm}^{3} / \mathrm{g} ; \mathrm{V}_{\mathrm{sd}}$ is the desorption gas, $\mathrm{cm}^{3} ; \mathrm{m}_{\mathrm{d}}$ is the total weight of sample, $\mathrm{g}$ ).

$$
\mathrm{V}_{\mathrm{r}}=\frac{\mathrm{V}_{\mathrm{sr}}}{\mathrm{m}_{\mathrm{r}}}
$$

(in the formula: $V_{r}$ is the residual gas content, $\mathrm{cm}^{3} / \mathrm{g} ; \mathrm{V}_{\mathrm{sr}}$ is the residual gas, $\mathrm{cm}^{3} ; \mathrm{m}_{\mathrm{r}}$ is the residual gas sample weight, $\mathrm{g}$ )。

The estimate of the lost gas is an important factor, which will affect the accuracy and precision of the direct measurement of shale gas. In currently the most widely used in industry is the USBM Linear regression method to estimate the lost gas, which was developed by United States Bureau of Mines. The estimate of the lost gas use the accumulative total desorption gas in standard condition 
as the ordinate, and the square root of time as the abscissa to drawing in the current standard SY/T6940-2013, As shown in figure 2.In the figure the absolute value of the intercept of reverse extension cord and the longitudinal axis is the lost gas. The formula of lost gas is formula (4):

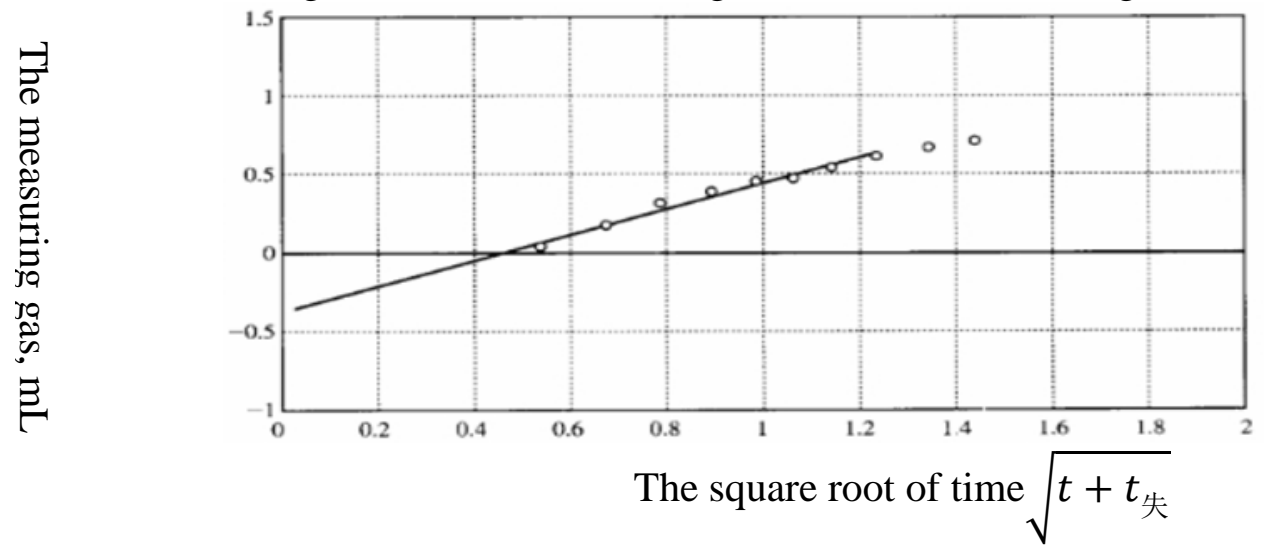

Fig.2 USBM direct method to calculate the lost gas (Linear regression method, )

$$
V_{s l}=k \sqrt{t+t_{l}}-V_{\mathrm{sd}}
$$

(in the formula: $\mathrm{V}_{\mathrm{sl}}$ is the lost gas, $\mathrm{cm}^{3} ; \mathrm{k}$ is the straight slope; $\mathrm{t}$ is the desorption time, min; $t_{l}$ is the lost time, min; $V_{s d}$ is the desorption gas, $\mathrm{cm}^{3}$ ).

Thus the lost gas content is:

$$
V_{l}=\frac{V_{s l}}{m_{d}}
$$

(in the formula: $V_{l}$ is the lost gas, $\mathrm{cm}^{3} ; m_{d}$ is the total weight of the sample, g). Thus the shale gas content is:

$$
V_{\mathrm{G}}=V_{d}+V_{r}+V_{l}
$$

\section{Shale gas measuring device}

In the shale gas content measurement process, precision of the measurement device is another important factor to affect gas metering accuracy. According to the survey, most of Shale gas content measurement device used in current site is manual measuring instrument based on principle of drainage method. As shown in figure 3, is testing system of Schematic for shale gas content. The instrument is composed of constant temperature device, desorption tank, hose, gas measurement test device, gas collecting device, the barometer and thermometer. Principle of this type of instrument structure is simple and the cost is lower, but in the process of measurement, the instrument has the low degree of automation and bigger error.

With the fast speed of the process of industrial automation, in recent years, a large number of automatic shale gas content measurement device with diversified measuring principle have been developed. At present, shale gas content automatic measurement devices ,existing in the market, are generally based on the principle of drainage, PVTt, gas meter method and differential pressure method, also the devices have the high measuring efficiency and precision , realized measuring shale gas content of unmanned automatic measurement. As shown in figure 4, is a drainage method based on the principle to realize automatic shale gas content measurement device designed by China University of Geosciences (Wuhan), including desorption device, gas detection device, data acquisition box and the upper machine. In the process of shale gas content measurement, put the sample in the desorption canister. The detection device includes metering cylinder, gas cylinder and pressure sensor. Shale gas collected by the air collector impress the liquid from the bottle into the metering cylinder ,calculating the pressure measurement, at the same time, data acquisition box will send detected signals of gas collected by detection device through the A/D conversion to the PC, 
the PC displays the signals ,and storage, and analysis. So as to realize the purpose of automatic control and automatic measurement. its measurement precision can reach $0.3 \mathrm{~mL}$.

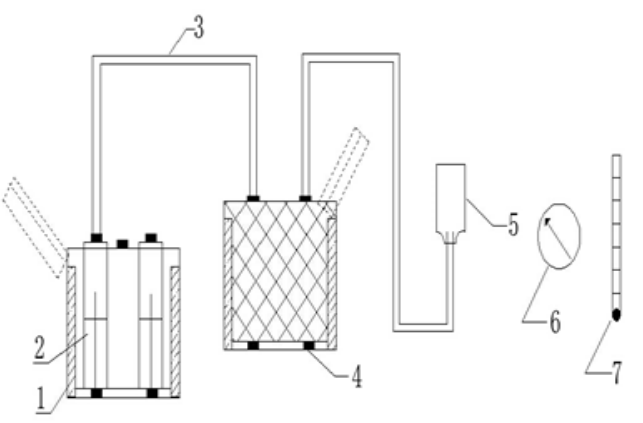

Fig.3 Shale Gas testing system

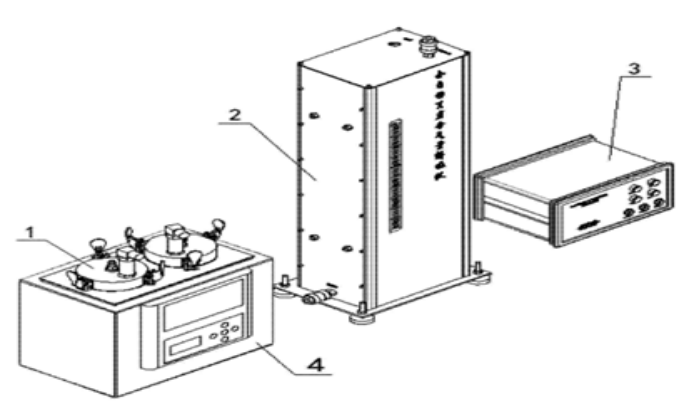

Fig.4 Automatic shale gas Analyzer

In 2013, Beijing HTSH energy technology co., LTD introduced a new type of shale gas content tester based on the principle of PVTt, this instrument has realized the automatic measurement, can determine more accurately the air content of low air content of sample, its measuring accuracy is high, and it can achieve that 16 road test at the same time. In 2015, Yu Lingjie and others used self developed intelligent shale gas field desorption instrument to optimize the existing conventional desorption method, and put forward $110{ }^{\circ} \mathrm{C}$ as the second-order desorption temperature, and formed a high temperature and fast desorption method, and reduced desorption time to about 8h, and can no longer test residual gas. It overcomes the difficulty in the long time of conventional desorption process, and effectively improves the measurement efficiency of shale gas content.

\section{Conclusion and Cognition}

Through the current situation about the exploration and exploitation of the global renewable energy resources to be seen, shale gas is the most realistic resource which can replace the common oil and gas resources. The measurement of shale gas content has a direct effect on economic calculation and evaluation works of reserves.

Shale gas in China in its infancy now, and with many questions unknown. How to develop the automaticity, reduce desorption time, get a higher efficiency and precision, and build a consummate automatic measuring system of shale gas content is a research emphasis for now.

\section{References}

[1] SY/T 6940 - 2013, Method for determination of shale gas [S].

[2] Zhang Jinchuan, Jin Zhiyun .etc. Reservoiring mechanism and distribution of shale gas [J]. Natural Gas Industry, 2004,24 (7): 15-18.

[3] Wang Xiangzeng. Lacustrine Shale Gas[M].Beijing : Petroleum Industry Press , 2014:1-8,112-142.

[4] Tang Ying, Zhang Jinchuan .etc. Shale Gas desorption measurement method and its improvement [J]. Natural Gas Industry, 2011, 31 (10): 108-112.

[5] Qin Xiaoyan. Analysis method to determine the lost gas in shale gas [J]. Groundwater, 2015,37(1): 231-232.

[6] China University of Geosciences (Wuhan). Automatic analysis of shale gas tester [P].China: CN 103900928 A, 2014.07.02.

[7] Beijing HTSH energy technology co., LTD. A new shale gas detector [P].China: CN 103063545 A, 2013.04.24.

[8] Yu Lingjie, Fan Ming .etc. Shale gas field desorption method optimization [J]. Experiment of Petroleum Geology, 2015,37(3): 402-406. 